\title{
Targeting the ataxia telangiectasia mutated pathway for effective therapy against hirsutine-resistant breast cancer cells
}

\author{
CHENGHUA LOU, SATORU YOKOYAMA, SHERIF ABDELHAMED, IKUO SAIKI and YOSHIHIRO HAYAKAWA
}

\author{
Division of Pathogenic Biochemistry, Department of Bioscience, Institute of Natural Medicine, \\ University of Toyama, Toyama 930-0194, Japan
}

Received March 26, 2015; Accepted April 15, 2016

DOI: $10.3892 / \mathrm{ol} .2016 .4554$

\begin{abstract}
The present authors have recently demonstrated that hirsutine, one of the major alkaloids in Uncaria species, promotes cell apoptosis by inducing DNA damage and suppresses metastasis of breast cancer cells. Despite its potent anti-cancer activity, certain types of human breast cancer cells exhibit resistance to hirsutine. To maximize the clinical utility of hirsutine therapy against breast cancer, it is critical to explore the underlying mechanism that protects hirsutine-resistant breast cancer cell lines. To identify potential targets for overcoming hirsutine-resistance, the present study investigated a library of kinase inhibitors in combination with hirsutine treatment in the hirsutine-resistant human breast carcinoma MCF-7 cell line. Amongst the 96 compounds tested, inhibitors of the ataxia telangiectasia mutated (ATM) pathway sensitized MCF-7 cells to hirsutine-induced cell death along with a sustained DNA damage response. This sensitization of MCF-7 cells to the hirsutine-induced DNA damage response by interfering with the ATM pathway did not require p53. Instead, radical oxygen species generation was significantly increased in hirsute and ATM inhibitor-treated MCF-7 cells. In conclusion, the present findings suggest the importance of the ATM pathway for optimizing the anti-cancer effect of hirsutine in breast cancer cells.
\end{abstract}

\section{Introduction}

Breast cancer comprises the most commonly diagnosed type of cancer and one of the leading cause of cancer-induced mortality in women worldwide (1). Despite current advances in therapeutic strategies against cancer, drug resistance remains a significant challenge; therefore, a combination of target-specific agents may be required to effectively eliminate

Correspondence to: Dr Yoshihiro Hayakawa, Division of Pathogenic Biochemistry, Department of Bioscience, Institute of Natural Medicine, University of Toyama, Sugitani 2630, Toyama 930-0194, Japan

E-mail: haya@inm.u-toyama.ac.jp

Key words: hirsutine, ATM, DNA damage, p53, ROS these cells (2). Chemotherapy is one of the most effective treatment strategies against cancer; however, cancer cells often acquire a resistance to chemotherapy, therefore continuing to grow and metastasize (3). Hirsutine, one of the major alkaloids in Uncaria species, is known for its cardioprotective, antihypertensive and antiarrhythmic activity $(4,5)$. The present authors previously demonstrated the anti-cancer effect of hirsutine in breast cancer cells $(6,7)$; however certain human breast cancer cell lines, including MCF-7, exhibited resistance against hirsutine-induced cytotoxicity.

The present study used a chemical screening approach and identified that the ataxia telangiectasia mutated (ATM) pathway is key for hirsutine-resistance in human breast carcinoma MCF-7 cells. The DNA damage response was significantly amplified in MCF-7 cells following co-treatment with hirsutine and KU-60019, a specific ATM inhibitor. While sensitization to hirsutine-induced DNA damage response in MCF-7 cells by interfering with the ATM pathway did not require p53, reactive oxygen species (ROS) generation was significantly increased in hirsute and ATM inhibitor-treated MCF-7 cells.

\section{Materials and methods}

Reagents. Hirsutine and a Cell Counting kit were purchased from Wako Pure Chemical Industries, Ltd. (Osaka, Japan) and KU-60019 was purchased from AdooQ Bioscience LLC (Irvine, CA, USA). Muse ${ }^{\mathrm{TM}}$ Oxidative Stress kit was purchased from EMD Millipore (Billerica, MA, USA). The SCADS Inhibitor kit (No. 3) was provided by the Screening Committee of Anticancer Drugs (Tokyo, Japan). The expression vector for the p53 dominant negative mutant (pBABEpuro-p53DD) and pBABEpuro (control) were kindly gifted by Dr David E. Fisher (Massachusetts General Hospital, Boston, MA, USA).

Cell culture and stable transfection. Human breast carcinoma MCF-7 cells were maintained in Dulbecco's modified Eagle's medium (DMEM) containing 10\% bovine serum (Nissui Pharmaceutical Co., Ltd., Tokyo, Japan). The cells were incubated at $37^{\circ} \mathrm{C}$ in a humidified atmosphere of $95 \%$ air and $5 \% \mathrm{CO}_{2}$. MCF-7 cells stably expressing dominant negative p53 were established as described previously (8). Briefly, MCF-7 cells were transfected with pBABEpuro (control) or pBABEpuro-p53DD, which contains the p53 dominant negative 
mutant using Lipofectaimne 2000 (Invitrogen; Thermo Fisher Scientific, Inc., Waltham, MA, USA). The cells were selected by puromycin $(100 \mu \mathrm{g} / \mathrm{ml}$; Sigma-Ardrich, St. Louis, MO, USA) for 14 days. Subsequently, puromycin-resistant clones were isolated using sterilized cloning rings (Sigma-Ardrich) and expanded as established MCF-7 $7^{\text {TRL }}$ and MCF-7 $7^{\text {p3DD }}$ cell lines. These cells were maintained in DMEM with puromycin $(100 \mu \mathrm{g} / \mathrm{ml})$. Dominant negative p53 expression was confirmed by western blot analysis.

Cell viability assay. MCF-7 $7^{\mathrm{CTR}}, \mathrm{MCF}-7^{\mathrm{p} 53 \mathrm{DD}}$ and MCF-7 cells were plated at a final concentration of $2 \times 10^{4}$ cells/well in a 96-well plate. After a $3 \mathrm{~h}$ incubation, the cells were treated with single or dual agents from the SCADs Inhibitor kit for $24 \mathrm{~h}$. For a combination assay, all cells were pretreated with the inhibitor for $1 \mathrm{~h}$. Following treatment, $10 \mu \mathrm{l} \mathrm{WST-1} \mathrm{Cell}$ Proliferation reagent (WST-1, Dojindo, Tokyo, Japan) was added. The 96-well plate was incubated for another $2 \mathrm{~h}$ in a humidified atmosphere $\left(37^{\circ} \mathrm{C} ; 5 \% \mathrm{CO}_{2}\right)$ to allow the formation of formazan dye and to obtain a higher sensitivity. The absorbance was measured in a microplate reader (Sunrise ${ }^{\mathrm{TM}}$; Tecan Group Ltd., Männedorf, Switzerland) at a wavelength of 450/620 nm. Cell viability was determined from the absorbance of soluble formazan dye generated by the living cells.

Western blot analysis. MCF-7 $7^{\mathrm{CTRL}}, \mathrm{MCF}-7^{\text {p53DD }}$ and MCF-7 cells (American Type Culture Collection, Manassas, VA, USA) were exposed to single or dual agents for $0,3,6$ and $12 \mathrm{~h}$. Treated cells were collected, washed with phosphate buffered saline (PBS) and lysed in lysis buffer $[25 \mathrm{mM}$ HEPES (pH, 7.7), $0.3 \mathrm{M} \mathrm{NaCl}, 1.5 \mathrm{mM} \mathrm{MgCl}_{2}, 0.2 \mathrm{mM}$ EDTA, $0.1 \%$ Triton $\mathrm{X}-100,20 \mathrm{mM} \beta$-glycerophosphate, $0.1 \mathrm{mM}$ sodium orthovanadate, $0.5 \mathrm{mM}$ phenylmethylsulfonyl fluoride, $1 \mathrm{mM}$ dithiothreitol, $10 \mathrm{mg} / \mathrm{ml}$ aprotinin, and $10 \mathrm{mg} / \mathrm{ml}$ leupeptin; Cell Signaling Technology, Danvers, MA USA]. The cell lysates were separated by $5-10 \%$ sodium dodecyl-sulfate polyacrylamide gel electrophoresis and transferred to polyvinylidene difluoride membranes using a glycine transfer buffer $[192 \mathrm{mM}$ glycine, $25 \mathrm{mM}$ Tris- $\mathrm{HCl}$ ( $\mathrm{pH}, 8.8)$, and $20 \%$ (v/v) methanol; Sigma-Aldrich]. After blocking with Block Ace (DS Biomedical, Osaka, Japan) for $4 \mathrm{~h}$ at room temperature, the membrane was incubated overnight at $4^{\circ} \mathrm{C}$ with primary antibodies, and subsequently for $60 \mathrm{~min}$ at room temperature with secondary antibodies. Primary and secondary antibodies were used at a dilution of 1:1,000 and 1:2,000, respectively, and the proteins were visualized with an Amersham ECL Western Blotting Detection kit (GE Healthcare Life Sciences, Chalfont, UK).

The following antibodies were purchased from Cell Signaling Technology, Inc.: Rabbit monoclonal anti-phospho-ATM (Ser1981; catalog no., 5883) and rabbit monoclonal anti-phospho-histone H2A.X (Ser139; catalog no., 9947). Goat polyclonal anti-actin (catalog no., sc-1615) and goat polyclonal anti- $\alpha$-tubulin (catalog no., sc-31779) were purchased from Santa Cruz Biotechnology (Dallas, TX, USA). Mouse monoclonal anti-p53 (PAb421; catalog no., OP03) was purchased from Calbiochem ${ }^{\circledast}$ (EMD Millipore).

ROS measurement. MCF-7 cells were grown in 12-well plates and cultured overnight to allow adherence. Subsequently, the

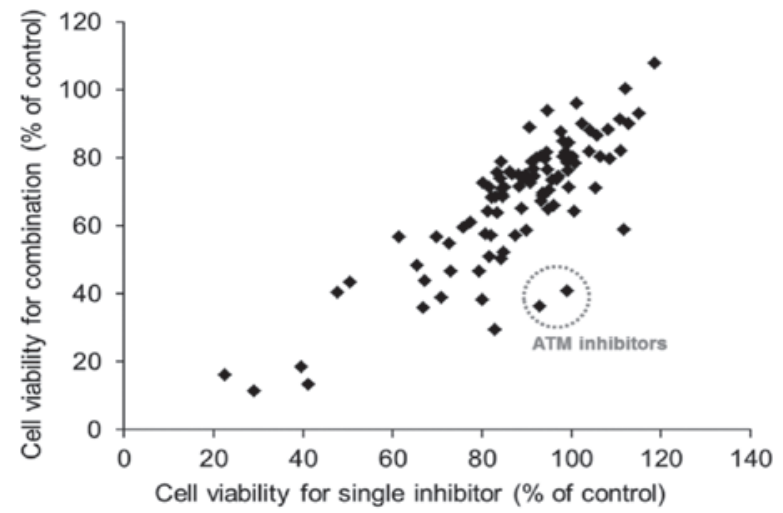

Figure 1. Resistance mechanism of human breast carcinoma MCF-7 cells against hirsutine. MCF-7 cells were treated with an inhibitor alone $(10 \mu \mathrm{M})$ or in combination with hirsutine $(50 \mu \mathrm{M})$ for $24 \mathrm{~h}$. For the combination assay, cells were pretreated with the inhibitor for $1 \mathrm{~h}$ followed by the addition of hirsutine. Data are representative of three independent experiments.

cells were treated with single or dual agents for an additional $30 \mathrm{~min}$. The cells were collected and washed twice with PBS and resuspended in 1X Assay Buffer and $190 \mu$ l oxidative stress working solution from the Muse ${ }^{\mathrm{TM}}$ Oxidative Stress kit were added to $10 \mu \mathrm{l}$ cells. The cells were incubated at $37^{\circ} \mathrm{C}$ for 30 min prior to analysis with a Muse ${ }^{\mathrm{TM}}$ Cell Analyzer (EMD Millipore). The assay was conducted in triplicate and in accordance to the manufacturer's protocol.

Statistical analysis. All data are expressed as the mean \pm standard deviation of at least three independent experiments and were analyzed for statistical significance using the Student's t-test. Statistical analysis was performed using Microsoft Excel 2013 (Microsoft Corporation, Redmond, WA, USA) $\mathrm{P}<0.05$ were considered to indicate a statistically significant difference.

\section{Results}

Protective role of the ATM pathway for hirsutine-induced cytotoxicity in MCF-7 cells. As previously reported, human epidermal growth factor (HER2) ${ }^{+} / \mathrm{p} 53$-mutated MDA-MB-453 and BT474 cell lines exhibit a response to hirsutine-induced cytotoxicity, whereas HER2 ${ }^{+} / \mathrm{p} 53$ wild-type MCF-7 cells exhibit significant resistance to hirsutine treatment $(6,7)$. To investigate the potential molecular pathway that contribute to hirsutine resistance in MCF-7 cells, the present study evaluated the kinase inhibitor compounds in a SCADS Inhibitor kit, which are listed in Table I, and their effect on the viability of MCF-7 cells in combination with hirsutine treatment. As shown in Fig. 1, ATM inhibitors exhibited a significant effect in sensitizing hirsutine-induced cytotoxicity in MCF-7 cells among the tested compounds. To additionally confirm the involvement of the ATM pathway in hirsutine resistance of MCF-7 cells, KU-60019, a second generation specific ATM inhibitor (9-11), was tested at a non-toxic dose $(\sim 20 \mathrm{mM})$ on its own (Fig. 2A) and in combination with hirsutine (Fig. 2B). As shown in Fig. 2B, KU-60019 exhibited a significant synergistic cytotoxic effect with hirsutine on MCF-7 cells ( $\mathrm{P}<0.05$ hirsutine treated cells vs. hirsutine and KU-60019 cells). 
Table I. Kinase inhibitors from the Screening Committee of Anticancer Drug Inhibitor kit.

\begin{tabular}{|c|c|c|}
\hline No. & Category & Compound \\
\hline 1 & Control & Dimethyl sulfoxide \\
\hline 2 & $\mathrm{AK}$ & ABT-702 \\
\hline 3 & AKT & Akt inhibitor IV \\
\hline 4 & $\mathrm{AKT}$ & Akt inhibitor VIII \\
\hline 5 & $\mathrm{AKT}$ & Akt inhibitor XI \\
\hline 6 & AMPK & Compound $\mathrm{C}$ \\
\hline 7 & ATM & ATM/ataxia telangiectasia kinase inhibitor \\
\hline 8 & ATM & ATM kinase inhibitor \\
\hline 9 & Aurora & Aurora kinase/Cdk inhibitor \\
\hline 10 & Aurora & Aurora kinase inhibitor II \\
\hline 11 & Aurora & Aurora kinase inhibitor III \\
\hline 12 & Bcr-Abl & AG957 \\
\hline 13 & BTK & LFM-A13 \\
\hline 14 & BTK & Terreic acid \\
\hline 15 & CAMKII & KN-93 \\
\hline 16 & CAMKII & $\mathrm{KN}-62$ \\
\hline 17 & CAMKII & Lavendustin $\mathrm{C}$ \\
\hline 18 & CDK & Kenpaullone \\
\hline 19 & CDK & Purvalanol A \\
\hline 20 & CDK & Olomoucine \\
\hline 21 & CDK & Alsterpaullone, 2-cyanoethyl \\
\hline 22 & CDK & Cdk1/2 inhibitor III \\
\hline 23 & CDK & Cdk2/9 inhibitor \\
\hline 24 & CDK & NU6102 \\
\hline 25 & CDK & Cdk4 inhibitor \\
\hline 26 & CDK & NSC625987 \\
\hline 27 & Chk & SB218078 \\
\hline 28 & Chk & Isogranulatimide \\
\hline 29 & Chk & Chk2 inhibitor \\
\hline 30 & Chk & Chk2 inhibitor II \\
\hline 31 & $\mathrm{CK}$ & Ellagic acid \\
\hline 32 & CK & TBB \\
\hline 33 & CK & DMAT \\
\hline 34 & CK & D4476 \\
\hline 35 & Clk & TG003 \\
\hline 36 & DGK & DGK inhibitor II \\
\hline 37 & DNA-PK & IC60211 \\
\hline 38 & $\mathrm{eEF} 2$ & TX-1918 \\
\hline 39 & EGFR & BPIQ-II \\
\hline 40 & EGFR & AG1478 \\
\hline 41 & EGFR & AG490 \\
\hline 42 & FGFR & SU4984 \\
\hline 43 & FGFR & SU5402 \\
\hline 44 & Flt-3 & Flt-3 inhibitor \\
\hline 45 & FMS & cFMS receptor tyrosine kinase inhibitor \\
\hline 46 & Fyn & SU6656 \\
\hline 47 & GSK & GSK-3 inhibitor IX \\
\hline 48 & GSK & 1-Azakenpaullone \\
\hline 49 & GSK & Indirubin-3'-monoxime \\
\hline 50 & HER2 & AG825 \\
\hline
\end{tabular}

Table I. Continued.

\begin{tabular}{|c|c|c|}
\hline No. & Category & Compound \\
\hline 51 & IGF-IR & AG1024 \\
\hline 52 & IGF-IR & AGL 2263 \\
\hline 53 & IKK & BMS-345541 \\
\hline 54 & IKK & IKK-2 inhibitor VI \\
\hline 55 & IRAK & IRAK-1/4 inhibitor \\
\hline 56 & Jak & JAK inhibitor I \\
\hline 57 & Jak & JAK3 inhibitor VI \\
\hline 58 & JNK & SP600125 \\
\hline 59 & JNK & JNK inhibitor VIII \\
\hline 60 & Lck & Damnacanthal \\
\hline 61 & Lck & PP2 \\
\hline 62 & MAPK & ERK inhibitor II \\
\hline 63 & MEK & PD98059 \\
\hline 64 & MEK & U-0126 \\
\hline 65 & MEK & MEK inhibitor I \\
\hline 66 & Met & SU11274 \\
\hline 67 & MLCK & ML-7 \\
\hline 68 & p38 & SB202190 \\
\hline 69 & p38 & SB239063 \\
\hline 70 & PDGFR & AG1296 \\
\hline 71 & PDGFR & SU11652 \\
\hline 72 & PDGFR & PDGF receptor tyrosine kinase inhibitor $\mathrm{V}$ \\
\hline 73 & PDGFR & PDGF receptor tyrosine kinase inhibitor IV \\
\hline 74 & $\mathrm{PI} 3 \mathrm{~K}$ & LY-294002 \\
\hline 75 & $\mathrm{PI} 3 \mathrm{~K}$ & Wortmannin \\
\hline 76 & PKA & H-89 \\
\hline 77 & PKA & 4-Cyano-3-methylisoquinoline \\
\hline 78 & $\mathrm{PKC}$ & Bisindolylmaleimide I, $\mathrm{HCl}$ \\
\hline 79 & $\mathrm{PKC}$ & Go7874 \\
\hline 80 & $\mathrm{PKG}$ & Rp-8-CPT-cGMPS \\
\hline 81 & PKG & KT5823 \\
\hline 82 & PKR & PKR inhibitor \\
\hline 83 & Raf & RAF1 kinase inhibitor I \\
\hline 84 & Raf & ZM 336372 \\
\hline 85 & ROCK & H-1152 \\
\hline 86 & ROCK & Y-27632 \\
\hline 87 & Hsp90 & Radicicol \\
\hline 88 & Src & PP1 analog \\
\hline 89 & Syk & Syk inhibitor \\
\hline 90 & TGF- $\beta$ RI & SB431542 \\
\hline 91 & TGF- $\beta$ RI & TGF- $\beta$ RI kinase inhibitor II \\
\hline 92 & Tpl2 & Tpl2 kinase inhibitor \\
\hline 93 & TrKA & TrkA inhibitor \\
\hline 94 & VEGFR & VEGFR receptor tyrosine kinase inhibitor II \\
\hline 95 & VEGFR & VEGF recptor 2 kinase inhibitor I \\
\hline 96 & VEGFR & SU1498 \\
\hline
\end{tabular}

Involvement of the ATM pathway in hirsutine-induced cytotoxicity through modulation of the DNA damage response. Considering the DNA damage response was one of the 
A
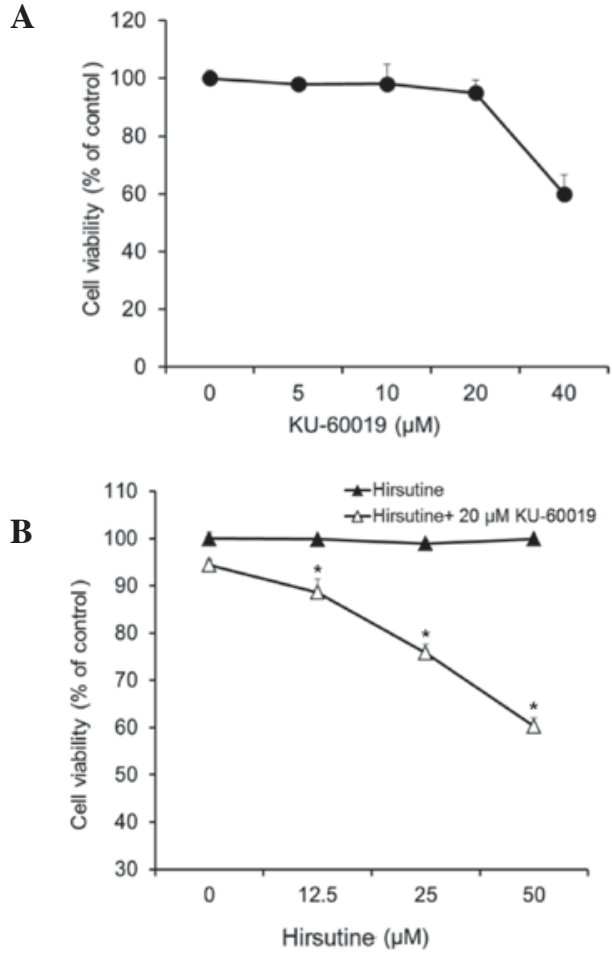

Figure 2. Ataxia telangiectasia mutated pathway inhibitor KU-60019 sensitized human breast carcinoma MCF-7 cells to hirsutine. (A) MCF-7 cells were treated with KU-60019 alone or (B) in combination with hirsutine for $24 \mathrm{~h}$. Cell viability was determined by WST-1 cell proliferation assay. Data are representative of three independent experiments. ${ }^{*} \mathrm{P}<0.05$ compared with hirsutine alone.

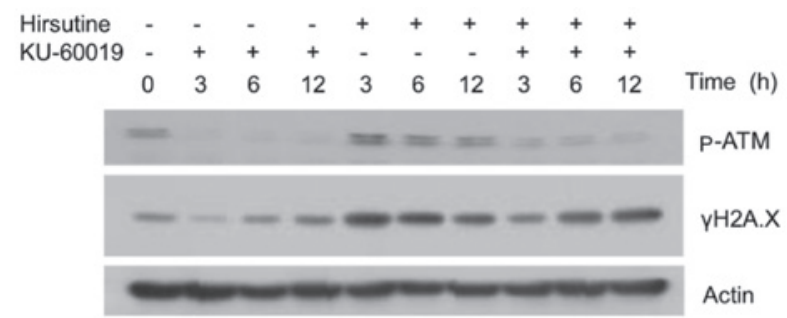

Figure 3. Treatment of human breast carcinoma MCF-7 cells with a combination of hirsutine and KU-60019 induced a DNA damage response. MCF-7 cells were treated with KU-60019 $(20 \mu \mathrm{M})$ alone or with hirsutine $(50 \mu \mathrm{M})$ for 0,3 , 6 and $12 \mathrm{~h}$. Cell lysates were collected and subjected to western blot analysis to detect the expression of DNA damage response-associated proteins. Data are representative of at least three independent experiments. ATM, ataxia telangiectasia mutated; $\mathrm{p}$, phospho.

mechanisms of hirsutine-induced cytotoxicity, the present study investigated whether a co-administration of hirsutine with KU-60019 also induces a DNA damage response in hirsutine-resistant MCF-7 cells. As shown in Fig. 3, hirsutine did not induce persistent activation of the DNA damage response, as observed by the expression of $\gamma \mathrm{H} 2 \mathrm{~A} . \mathrm{X}$ in MCF-7 cell. Notably, treatment with KU-60019 alone did have an affect; combination of hirsutine and KU-60019 significantly induced the persistent DNA damage response along with the suppression of ATM activation. Taken together with the cytotoxicity data, the present study concludes that interference of the ATM pathway is an important mechanism
A
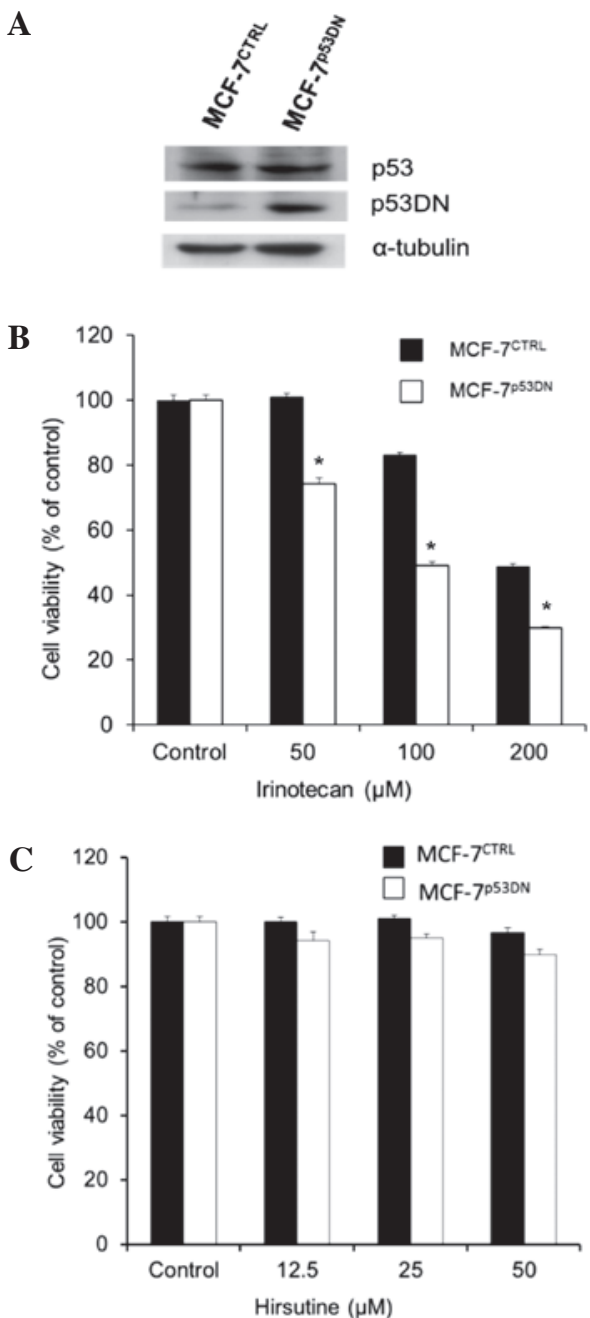

Figure 4. p53-independent resistance to hirsutine treatment in human breast carcinoma MCF-7 cells. (A) Expression of wild-type p53 or p53DN in MCF-7 ${ }^{\text {CTRL }}$ or MCF-7 ${ }^{\text {p53DN }}$ cells. (B and C) Effect of (B) irinotecan or (C) hirsutine on the viability of MCF-7 $7^{\mathrm{CTRL}}$ or MCF-7 ${ }^{\text {53DN }}$ cells treated with hirsutine $(50 \mu \mathrm{M})$. $^{*} \mathrm{P}<0.05$ compared with MCF-7CTRL cells. Data are representative of at least three independent experiments. p53DN, dominant negative p53; CTRL, control.

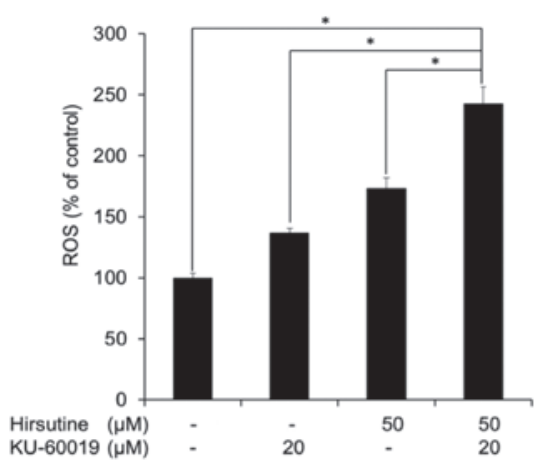

Figure 5. Combination of hirsutine and KU-60019 treatment induced accumulation of ROS in human breast carcinoma MCF-7 cells. MCF-7 cells were treated with KU-60019 $(20 \mu \mathrm{M})$ alone or in combination with hirsutine $(50 \mu \mathrm{M})$ for $30 \mathrm{~min}$, and ROS levels were evaluated. Data are representative of three independent experiments. ${ }^{*} \mathrm{P}<0.05$. ROS, reactive oxygen species.

for hirsutine-induced cytotoxicity by modulation of the DNA damage response. 
Hirsutine induces p53-independent DNA damage response and ROS generation in MCF-7 cells. Since $\mathrm{p} 53$ is a well known product of the DNA damage response, which induces cell death or repair and is expressed in hirsutine-resistant cell lines (12), the importance of p53 in ATM-dependent hirsutine-resistance of MCF-7 cells was examined by the present study using MCF-7 cells that overexpressed dominant-negative p53 (MCF-7 p53DN $^{\text {cells; Fig. 4A). While MCF-7p53D }}$ cells exhibited a higher sensitivity to irinotecan (Fig. 4B), which is a typical DNA damage-inducing agent, no difference was observed in the response between hirsutine-treated MCF-7 ${ }^{53 \mathrm{DN}}$ and MCF-7 ${ }^{\text {CTRL }}$ cells (Fig. 4C). Therefore, the present study concludes that inhibition of the ATM pathway did not require p53 to confer hirsutine-resistance of MCF-7 cells. By contrast, it is known that mitochondrial activity and ROS generation are major contributors for the p53-independent DNA damage response (13). Consequently, the ROS expression level in MCF-7 cells treated with hirsutine and KU-60019 was evaluated. As shown in Fig. 5, the ROS expression level was significantly increased following co-treatment with hirsute and KU-60019 compared with cells treated with hirsutine or KU-60019 alone. Collectively, the present data indicate the potential utility of interfering with the ATM pathway to overcome hirsutine resistance by inducing p53-independent DNA damage response and ROS generation in MCF-7 cells.

\section{Discussion}

The DNA damage response is one molecular event that results in apoptosis, and consequently numerous anti-cancer agents induce a DNA damage response (14-18). Hirsutine, one of the major alkaloids in Uncaria species, exhibits an anti-metastatic effect in a murine breast cancer model (6) and has an anti-tumor effect on HER2 ${ }^{+}$breast cancer cells by inducing DNA damage (7). However, certain breast cancer cell lines, primarily hormone receptor (estrogen or progesterone receptor) positive breast cancer MCF-7 and ZR-75-1 cells, have exhibited resistance to hirsutine-induced cytotoxicity and the DNA damage response in previous studies $(6,7)$. The present study used a chemical screening approach, which identified that the ATM pathway is key for hirsutine-resistance in MCF-7 cells, and the DNA damage response is significantly amplified following co-treatment of hirsutine and KU-60019, a specific ATM inhibitor, in MCF-7 cells.

It has been widely recognized that the consequences resulting from the DNA damage response to induce cell death is counter regulated by the DNA repair response $(12,19,20)$. ATM kinases, key protein kinases for the DNA damage response, are known to regulate double-strand break repair $(21,22)$. In response to low levels of DNA damage, ATM kinases activate p53 to induce cell cycle arrest leading to successful DNA repair (19). In the present study, no difference was observed in the hirsutine response between p53 MCF-7 ${ }^{\text {p53DN }}$ and control cells. Therefore, the present study concludes that the sensitization to hirsutine-induced DNA damage response in MCF-7 cells by interfering with the ATM pathway is independent of $\mathrm{p} 53$. In addition to the p53-dependent DNA repair response, the ATM-ROS pathway has been previously reported to amplify a DNA-damaging response following genotoxic stress (23). In the present study, the level of ROS generation was significantly increased in MCF-7 cells treated with a combination of ATM inhibitor and hirsute. Considering p38 mitogen-activated protein kinase (MAPK) is known to be important in the DNA damage response induced by genotoxic stress with DNA-damaging chemotherapeutic agents (24) and a loss of ATM impairs the proliferation of stem cells through oxidative stress-mediated p38 MAPK signaling $(25,26)$, the present study hypothesizes that p38 MAPK stress signaling pathway possibly contributes to the sensitization of MCF-7 cells to the hirsutine-induced DNA damage response by interfering with the ATM pathway.

The present results indicate the potential utility of interfering with the ATM pathway to overcome hirsutine resistance in breast cancer cells, which induces a p53-independent DNA damage response and ROS generation.

\section{Acknowledgements}

This work is partly supported by a grant-in-aid for the Cooperative Research Project from the Institute of Natural Medicine, University of Toyama. The authors would like to thank the Screening Committee of Anticancer Drugs supported by a grant-in-aid for Scientific Research on Innovative Areas, Scientific Support Programs for Cancer Research (The Ministry of Education, Culture, Sports, Science and Technology; Tokyo, Japan) for the provision of the SCADS Inhibitor kit and Dr David E. Fisher for providing the expression vector for p53 dominant negative mutant. Mr. Chenghua Lou is supported by the Campus Asian Program of the University of Toyama.

\section{References}

1. Jemal A, Bray F, Center MM, Ferlay J, Ward E and Forman D: Global cancer statistics. CA Cancer J Clin 61: 69-90, 2011.

2. Trachootham D, Alexandre J and Huang P: Targeting cancer cells by ROS-mediated mechanisms: A radical therapeutic approach? Nat Rev Drug Discov 8: 579-591, 2009.

3. Holohan C, Van Schaeybroeck S, Longley DB and Johnston PG: Cancer drug resistance: An evolving paradigm. Nat Rev Cancer 13: 714-726, 2013.

4. Wu LX, Gu XF, Zhu YC and Zhu YZ: Protective effects of novel single compound, Hirsutine on hypoxic neonatal rat cardiomyocytes. Eur J Pharmacol 650: 290-297, 2011.

5. Horie S, Yano S, Aimi N, Sakai S and Watanabe K: Effects of hirsutine, an antihypertensive indole alkaloid from Uncaria rhynchophylla, on intracellular calcium in rat thoracic aorta. Life Sci 50: 491-498, 1992

6. Lou C, Takahashi K, Irimura T, Saiki I and Hayakawa Y: Identification of Hirsutine as an anti-metastatic phytochemical by targeting NF- $\mathrm{BB}$ activation. Int J Oncol 45: 2085-2091, 2014.

7. Lou C, Yokoyama S, Saiki I and Hayakawa Y: Selective anticancer activity of hirsutine against HER2-positive breast cancer cells by inducing DNA damage. Oncol Rep 33: 2072-2076, 2015.

8. Garraway LA, Widlund HR, Rubin MA, Getz G, Berger AJ, Ramaswamy S, Beroukhim R, Milner DA, Granter SR, Du J, et al: Integrative genomic analyses identify MITF as a lineage survival oncogene amplified in malignant melanoma. Nature 436: 117-122, 2005.

9. Golding SE, Rosenberg E, Valerie N, Hussaini I, Frigerio M, Cockcroft XF, Chong WY, Hummersone M, Rigoreau L, Menear KA, et al: Improved ATM kinase inhibitor KU-60019 radiosensitizes glioma cells, compromises insulin, AKT and ERK prosurvival signaling, and inhibits migration and invasion. Mol Cancer Ther 8: 2894-2902, 2009.

10. Golding SE, Rosenberg E, Adams BR, Wignarajah S, Beckta JM, O'Connor MJ and Valerie K: Dynamic inhibition of ATM kinase provides a strategy for glioblastoma multiforme radiosensitization and growth control. Cell Cycle 11: 1167-1173, 2012. 
11. Hickson I, Zhao Y, Richardson CJ, Green SJ, Martin NM, Orr AI, Reaper PM, Jackson SP, Curtin NJ and Smith GC: Identification and characterization of a novel and specific inhibitor of the ataxia-telangiectasia mutated kinase ATM. Cancer Res 64: 9152-9159, 2004.

12. Norbury CJ and Zhivotovsky B: DNA damage-induced apoptosis. Oncogene 23: 2797-2808, 2004.

13. Nair RR, Bagheri M and Saini DK: Temporally distinct roles of ATM and ROS in genotoxic-stress-dependent induction and maintenance of cellular senescence. J Cell Sci 128: 342-353, 2015.

14. Zhu H, Huang M, Yang F, Chen Y, Miao ZH, Qian XH, Xu YF, Qin YX, Luo HB, Shen X, et al: R16, a novel amonafide analogue, induces apoptosis and G2-M arrest via poisoning topoisomerase II. Mol Cancer Ther 6: 484-495, 2007.

15. Cai Y, Lu J, Miao Z, Lin L and Ding J: Reactive oxygen species contribute to cell killing and P-glycoprotein downregulation by salvicine in multidrug resistant K562/A02 cells. Cancer Biol Ther 6: 1794-1799, 2007.

16. Cai B, Lyu H, Huang J, Wang S, Lee CK, Gao C and Liu B: Combination of bendamustine and entinostat synergistically inhibits proliferation of multiple myeloma cells via induction of apoptosis and DNA damage response. Cancer Lett 335: 343-350, 2013.

17. Kudoh T, Kimura J, Lu ZG, Miki Y and Yoshida K: D4S234E, a novel p53-responsive gene, induces apoptosis in response to DNA damage. Exp Cell Res 316: 2849-2858, 2010.
18. Rudolf E, Kralova V, Rudolf K and John S: The role of p38 in irinotecan-induced DNA damage and apoptosis of colon cancer cells. Mutat Res 741-742: 27-34, 2013

19. Ljungman M: The DNA damage response-repair or despair? Environ Mol Mutagen 51: 879-889, 2010.

20. Roos WP and Kaina B: DNA damage-induced cell death by apoptosis. Trends Mol Med 12: 440-450, 2006.

21. Valerie K and Povirk LF: Regulation and mechanisms of mammalian double-strand break repair. Oncogene 22: 5792-5812, 2003.

22. Lavin MF: Ataxia-telangiectasia: From a rare disorder to a paradigm for cell signalling and cancer. Nat Rev Mol Cell Biol 9: 759-769, 2008.

23. Ito K, Takubo K, Arai F, Satoh H, Matsuoka S, Ohmura M, Naka K, Azuma M, Miyamoto K, Hosokawa K, et al: Regulation of reactive oxygen species by Atm is essential for proper response to DNA double-strand breaks in lymphocytes. J Immunol 178: 103-110, 2007.

24. Sanchez-Prieto R, Rojas JM, Taya Y and Gutkind JS: A role for the p38 mitogen-activated protein kinase pathway in the transcriptional activation of p53 on genotoxic stress by chemotherapeutic agents. Cancer Res 60: 2464-2472, 2000.

25. Kim J and Wong PK: Loss of ATM impairs proliferation of neural stem cells through oxidative stress-mediated p38 MAPK signaling. Stem Cells 27: 1987-1998, 2009.

26. Ito K, Hirao A, Arai F, Takubo K, Matsuoka S, Miyamoto K, Ohmura M, Naka K, Hosokawa K, Ikeda Y and Suda T: Reactive oxygen species act through p38 MAPK to limit the lifespan of hematopoietic stem cells. Nat Med 12: 446-451, 2006. 